\title{
Startschuss für AKADEMIE ONLINE 2021
}

Die Fortbildungsreihe „Akademie Online“ der Deutschen Röntgengesellschaft geht ins neue Jahr 2021 - und damit mittlerweile schon in ihr elftes! Das Erfolgsrezept: alle 2 Wochen am Dienstagabend gibt es hier Radiologie in "gut verdaubaren Happen“: eine Stunde - ein Thema - ein/e Top-Referent/in! Auch im Jahr 2021 wird so die Vielfalt der Radiologie wieder in einem abwechslungsreichen Programm dargestellt: Von A wie akutes Abdomen über P wie Polytrauma bis Z wie ZNS-Entzündungen. Pro Online-Kurs gibt es 2 CME-Punkte - bei ins- gesamt 25 ärztlichen Kursen pro Jahr können damit bis zu 50 CME-Punkte pro Jahr gesammelt werden. Wer das Jahresabo bucht, erhält Zugang zu insgesamt 25 Ärzte-Kursen und 12 MTRA-Kursen pro Jahr entweder jeweils live am Dienstagabend oder für verpasste Kurse als Aufzeichnung.

Das komplette Programm und die Möglichkeit zur Anmeldung finden Sie online unter www.drgakademie.de > Akademie Online.

\section{ACHTUNG}

\section{FRÜHBUCHER-FEBRUAR:}

Schnellentschlossene, die sich bis zum 29.01.2021 für das Jahresabo anmelden, können alle Kurse des Jahres 2020 für die Dauer von 4 Wochen im Februar noch einmal anschauen! 